\title{
Experts question usefulness of screening travellers to UK for Ebola
}

\author{
Anne Gulland \\ London
}

Experts have questioned the effectiveness of the UK government's announcement that it is going to introduce screening at major UK transport terminals in a bid to intercept travellers with Ebola disease.

The government made the announcement to stem fears over the potential spread of the disease in the United Kingdom, after a man in the United States died from the disease and a nurse caring for missionaries with the disease in Spain became infected. ${ }^{123}$ The US has also introduced screening at five major airports. ${ }^{4}$

Enhanced screening will initially be implemented at Heathrow and Gatwick airports and the Eurostar train terminals and will be conducted by medical rather than border force staff, the spokesman added.

Only travellers from the three affected countries-Sierra Leone, Liberia, and Guinea — will be screened, at first by a questionnaire that will assess passengers' recent travel history, their contacts, and onward travel arrangements. Travellers will then have more comprehensive screening if concerns are flagged up at this stage. A Downing Street spokeswoman said that details of the full screening arrangement were still being worked out.

Travellers leaving the three worst affected countries are already screened on exit, and virologists have questioned the effectiveness of entry screening. Ben Neumann, a lecturer in virology at Reading University, said that there was no strong scientific case that airport screening would keep Ebola disease out of the UK. He said, "Even for experienced doctors Ebola is a difficult disease to detect. [In] the first few weeks after infection a person would not normally have any external signs of having Ebola. Early stage Ebola cases could only be detected by an invasive blood test, and even that might fail if the person has very recently contracted the virus.

"The only surefire way to keep Ebola out of the UK is to stop it at the source, by measures like providing new hospitals, and people needed to mount a joined-up public health response in west Africa."

David Evans, professor of virology at Warwick University, said that it was important that screening did not create a false sense of security. He added that relying on temperature screening would identify many false positive cases of the disease.
He said, "Similarly, false negatives_-passengers arriving without a fever but who are infected with Ebola-would still escape detection. Use of temperature screening was not effective in identifying passengers with SARS [severe acute respiratory syndrome] during the 2003 epidemic, and there is no reason to think it would be any better in identifying passengers infected with Ebola," he said.

The decision to screen travellers was made by the government's Cobra crisis response team, comprising ministers, including the prime minister, chancellor of the exchequer, health secretary, international development secretary, England's chief medical officer, Sally Davies, and Paul Cosford, director of health protection at Public Health England.

A statement on the Public Health England website dated 7 October said that entry screening for Ebola would "require the UK to screen every returning traveller, as people could return to the UK from an affected country through any port of entry. This would be huge numbers of low risk people." The World Health Organization currently does not recommend entry screening.

After the government's announcement Davies said that the screening would "help to improve our ability to detect and isolate Ebola cases."

She said, "Although the risk to the UK remains low, in view of the concern about the growing number of cases it is right to consider what further measures could be taken, to ensure that any potential cases arriving in the UK are identified as quickly as possible."

Two doctors treating the Spanish nurse with Ebola disease, ${ }^{2}$ Teresa Romero, have been admitted for observation, taking the total number quarantined to six. Meanwhile, Spanish healthcare workers have been demonstrating over cuts to health services over recent years.

McCarthy M. Texas healthcare worker is diagnosed with Ebola. BMJ 2014;349:g6200 McCarthy M. Liberian man being treated for Ebola in Texas dies. BMJ 2014;349:g6145 Gulland A. Spanish authorities investigate how nurse contracted Ebola. BMJ 2014;349:g6120.

McCarthy M. US increases Ebola screening at five airports. BMJ 2014;349:g6147. 